\title{
Significance of ventricular late potentials in non-ischaemic dilated cardiomyopathy
}

\author{
D. Denereaz, M. Zimmermann and R. AdameC
}

Cardiology Center and Policlinic of Medicine, University Hospital, Geneva, Switzerland

KEY WORDS: Ventricular late potentials, signal-averaging, non-ischaemic dilated cardiomyopathy, ventricular tachycardia.

To assess the incidence and clinical significance of ventricular late potentials in non-ischaemic dilated cardiomyopathy, 51 consecutive (44 male, seven female, mean age $53 \pm 11$ years) patients with dilated cardiomyopathy were studied. Twentyeight patients (55\%) were in New York Heart Association functional class III or IV, 34 out of 51 (76\%) had a left ventricular ejection fraction of less than $40 \%, 10$ out of 51 (20\%) had a history of sustained ventricular tachycardia (VT), 24 out of $37(65 \%)$ had runs of non-sustained ventricular tachycardia during Holter monitoring and 15 out of $51(29 \%)$ had a left bundle branch block. A signal-averaged electrocardiogram (gain $10^{\circ} \times$, bipolar chest leads. filters $\left.100-300 \mathrm{~Hz}\right)$ was performed in all the patients; late potentials were considered present if the total filtered $Q R S$ duration was longer than $118 \mathrm{~ms}$ and the interval between the end of $Q R S$ and the voltage $40 \mu \mathrm{V}$ was more than $40 \mathrm{~ms}$ in the absence of left bundle branch block (total filtered $Q R S$ duration $>140 \mathrm{~ms}$ and interval between the end of $Q R S$ and the voltage $40 \mu \mathrm{V}>50 \mathrm{~ms}$ in the presence of left bundle branch block).

Ventricular late potentials were detected in 22 out of 51 patients (43\%). Late potentials were present in $80 \%$ (eight out of 10) of patients with sustained ventricular tachycardia but in only $34 \%$ (14 of 4l) without sustained ventricular tachycardia $(\mathrm{P}<0.01)$. This difference remained statistically significant even when patients with a left bundle branch block were excluded from the analysis ( 4 out of 6 vs 4 out of $30, \mathrm{P}<0.01$ ). To identify patients with dilated cardiomyopathy and sustained ventricular tachycardia, signal-averaging had a sensitivity of $80 \%$, a specificity of $66 \%$, a positive predictive value of $36 \%$ and a negative predictive value of $93 \%$.

It is concluded that, in non-ischaemic dilated cardiomyopathy, the signal-averaged electrocardiogram allows the identification of patients with sustained ventricular tachycardia, even in the presence of a left bundle branch block.

\section{Introduction}

Patients suffering from non-ischaemic dilated cardiomyopathy have a high incidence of serious ventricular arrhythmias and most of the deaths in this syndrome are sudden and unexpected, presumably related to malignant ventricular arrhythmias ${ }^{[1]}$. However, until now, no clinical predictors of sudden death have been identified, and the prognostic significance of Holter monitoring and programmed ventricular stimulation in this clinical entity is still controversial ${ }^{[2-9]}$.

During the last few years, signal-averaging for the detection of ventricular late potentials has emerged as a promising tool for identifying patients at high risk of serious ventricular arrhythmias or sudden death after myocardial infarction ${ }^{[10-13]}$. Ventricular late potentials are abnormal, low-amplitude, high-frequency signals, occurring in the terminal portion of the QRS complex and extending into the ST segment: these late potentials are thought to represent delayed activation of small areas of the diseased myocardium, and therefore, are considered as a marker for re-entry ${ }^{[11]}$. The purposes of the present study were to determine (a) the incidence of ventricular late potentials in a group of unselected patients with non-ischaemic dilated

Submitted for publication 30 April 1991, and in revised form 18 November 1991.

Correspondence: Marc Zimmermann, MD. Cardiology Center, Unıversity Hospital, 24 rue Micheli-du-Crest, 1211 Geneva 4, Switzerland. cardiomyopathy, (b) the association between late potentials and malignant ventricular tachyarrhythmias and (c) the possible role of late potentials detection in assessing the prognosis of patients with dilated cardiomyopathy.

\section{Methods}

PATIENTS

The study population consisted of 51 consecutive, unselected patients (44 male, seven female, mean age $53 \pm 11$ years, range $22-74$ years) with non-ischaemic dilated cardiomyopathy. Each patient had a complete physical examination, a standard 12-lead electrocardiogram, a chest $\mathrm{X}$-ray and a time-domain signal-averaged electrocardiogram. In addition, 45 out of 51 patients underwent cardiac catheterization with coronary arteriography; 47 out of 51 had 2-D echocardiography and 37 out of 51 patients $(73 \%$ ) had $24 \mathrm{~h}$ Holter monitoring (Del Mar Avionics two-channel recorder, model 447, semiautomated analysis using the Avionics Trendsetter, model $9000 \mathrm{~A}$ ). The diagnosis of dilated cardiomyopathy was based on (a) left ventricular ejection fraction of less than $50 \%$ (by angiographic left ventriculography) with no significant (luminal narrowing $<50 \%$ ) coronary stenosis ( $N=45$ out of 51) or (b) a left ventricular ejection fraction of less than $50 \%$ (by 2-D echocardiography), with diffuse hypokinesia, no segmental wall motion abnormality and no history of angina or myocardial infarction $(N=6$ out 
of 51). The presumed aetiology was chronic alcohol abuse in 13 cases, related to peripartum in two cases and idiopathic in 36 cases. A history of sustained ventricular tachycardia was present in 10 cases $(20 \%)$. At the time of recording, eight out of 51 patients were taking no medication, 28 were receiving angiotensin converting-enzyme inhibitors, 22 digoxin, 21 diuretics, 13 amiodarone and three were receiving $\beta$-blockers, alone or in combination.

\section{SIGNAL AVERAGING}

A time-domain signal-averaged electrocardiogram was performed in all patients using the signal averager used by our group and previously described ${ }^{[13]}$. Briefly, band-pass filters are set at 100 and $300 \mathrm{~Hz}\left(12 \mathrm{~dB}\right.$.octave $\left.\mathrm{e}^{-1}\right)$, the peak of the $R$ wave is used as a trigger (jitter $<0.5 \mathrm{~ms}$ ) and bipolar chest leads (between $\mathrm{V} 2$ and $\mathrm{V} 4$, between $\mathrm{V} 4$ and V6) are used. The averaging process is performed on 40 consecutive beats or more, in order to reduce the baseline noise to $0.4 \pm 0.2 \mu \mathrm{V}$. The recording $\left(2 \mu \mathrm{V} . \mathrm{cm}^{-1}\right)$ is plotted on paper (paper speed $1000 \mathrm{~mm} . \mathrm{s}^{-1}$ ) together with a reference electrocardiogram $\left(200 \mu \mathrm{V} . \mathrm{cm}^{-1}\right)$. Quantitative analysis includes (a) total filtered QRS duration (ms) and (b) the interval between the end of the total QRS complex and the point (determined in a retrograde manner) when QRS voltage falls below $40 \mu \mathrm{V}$ (I-40, in ms). QRS onset and offset were manually determined and all tracings were interpreted by two different investigators without knowledge of the patient's condition.

\section{DEFINITIONS}

Non-sustained ventricular tachycardia was defined as ventricular tachycardia lasting less than $30 \mathrm{~s}$ and terminating spontaneously. Sustained ventricular tachycardia was defined as ventricular tachycardia lasting more than 30 sor requiring immediate DC shock because of haemodynamic compromise. Sudden death was defined as death occurring within $1 \mathrm{~h}$ of symptom onset in a clinically stable patient or unexpected death occurring during sleep. Ventricular late potentials were defined as high-frequency, low amplitude signals appearing during the terminal portion of the QRS or on the ST segment. Ventricular late potentials were considered to be present if (a) in the absence of left bundle branch block, total filtered QRS duration is more than $118 \mathrm{mms}$ and I-40 is more than $45 \mathrm{~ms}$ (maximal value for normal subjects in the laboratory); and (b) in the presence of left bundle branch block, total QRS duration is more than $140 \mathrm{~ms}$ and $\mathrm{I}-\mathbf{4 0}$ is at least $50 \mathrm{~ms}$.

\section{FOLLOW-UP}

Follow-up assessment included clinical information obtained by questionnaire or telephone from the attending physician and/or from any hospital the patient was admitted to during the follow-up period.

\section{STATISTICAL ANALYSIS}

Values are expressed as means \pm standard deviation (SD). Results were analysed using the unpaired t-test and chi-square when appropriate. A $P$ value of less than 0.05 was considered statistically significant.

\section{Results}

\section{CLINICAL AND HAEMODYNAMIC DATA}

Twenty-eight out of 51 patients $(55 \%)$ showed clinical signs of heart failure (New York Heart Association functional class IV in 22 and class III in six). In patients for whom haemodynamic data were available $(N=45)$, the mean left ventricular ejection fraction was $32 \pm 12 \%$, range $10-50 \%$, and the ejection fraction less than $40 \%$ in 34 cases $(76 \%)$. The mean end-diastolic volume index was $152 \pm 49 \mathrm{ml} \cdot \mathrm{m}^{-2}$ and the mean left ventricular enddiastolic pressure $19 \pm 8 \mathrm{mmHg}$. A left bundle branch block was present in 15 out of 51 patients $(29 \%)$, and 17 out of 51 patients $(33 \%)$ had non-specific intraventricular conduction disturbances. The mean standard QRS duration on the surface electrocardiogram was $105 \pm$ $28 \mathrm{~ms}$ (range $80-180 \mathrm{~ms}$ ) and the mean QTc interval was $357 \pm 45 \mathrm{~ms}$ (range $280-480 \mathrm{~ms}$ ). Permanent atrial fibrillation was present in 10 out of 51 patients (20\%).

\section{HOLTER MONITORING DATA $(N=37)$}

Numerous (more than $30 . \mathrm{h}^{-1}$ ) premature ventricular complexes were observed in 19 patients $(51 \%)$, polymorphous premature ventricular complexes in $25(68 \%)$, ventricular couplets in $28(76 \%)$ and episodes of nonsustained ventricular tachycardia in $24(65 \%)$.

\section{SIGNAL-AVERAGING DATA $(N=51)$}

Using the aforementioned criteria, 22 patients $(43 \%)$ had ventricular late potentials (Fig. 1,2). These were present in eight out of 36 patients with no left bundle branch block $(22 \%)$ and in 14 out of $15(93 \%)$ patients with left bundle branch block (Fig. 3). Compared to patients without late potentials, patients with late potentials more often had a left bundle branch block pattern and a history of sustained ventricular tachycardia (Table 1). When patients with a left bundle branch block were excluded from data analysis, the presence of ventricular late potentials was still associated with a history of sustained ventricular tachycardia (Table 2).

When comparing the clinical characteristics of patients with and without a history of sustained ventricular tachycardia, the only significant difference between the two groups was the presence of ventricular late potentials: eight out of $10(80 \%)$ in the group with sustained ventricular tachycardia vs 14 out of $41(34 \%)$ in the group without sustained ventricular tachycardia $(P<0.01)$ (Table 3$)$. When patients with a left bundle branch block were excluded from data analysis, similar results were obtained and the quantitative parameters of the signal-averaged electrocardiogram allowed patients with and without sustained ventricular tachycardia to be distinguished (Table 4).

To identify patients who had sustained ventricular tachycardia, the presence of late potentials had a sensitivity of $80 \%$, a specificity of $66 \%$, a positive predictive value of $36 \%$ and a negative predictive value of $93 \%$. These results compared favourably with the results of physical examination, 12-lead electrocardiogram, Holter 


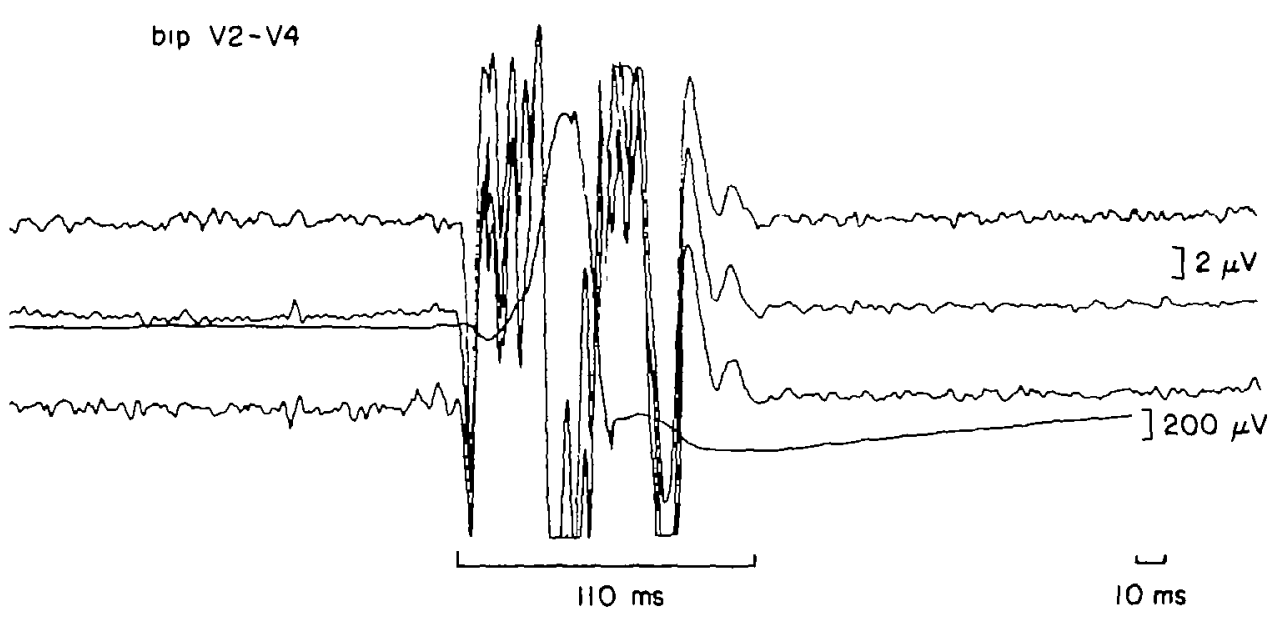

Figure I Signal-averaged electrocardiogram obtained in a 63-year-old patient with non-ischaemic dilated cardiomyopathy, no bundle branch block and no history of sustained ventricular tachycardia. Bipolar chest lead between $\mathrm{V} 2$ and $\mathrm{V} 4$; filters $100-300 \mathrm{~Hz}$; paper speed $1000 \mathrm{~mm} . \mathrm{s}^{-1}$. Three successive high-gain recordings $\left(2 \mu \mathrm{V} . \mathrm{cm}^{-1}\right)$ are displayed (each one obtaned by averaging 40 consecutive cardiac cycles) together with a reference electrocardiogram $\left(200 \mu \mathrm{V} . \mathrm{cm}^{-1}\right)$. The total filtered QRS duration is $110 \mathrm{~ms}$ and no lowamplitude/high-frequency components are present in the terminal QRS complex.

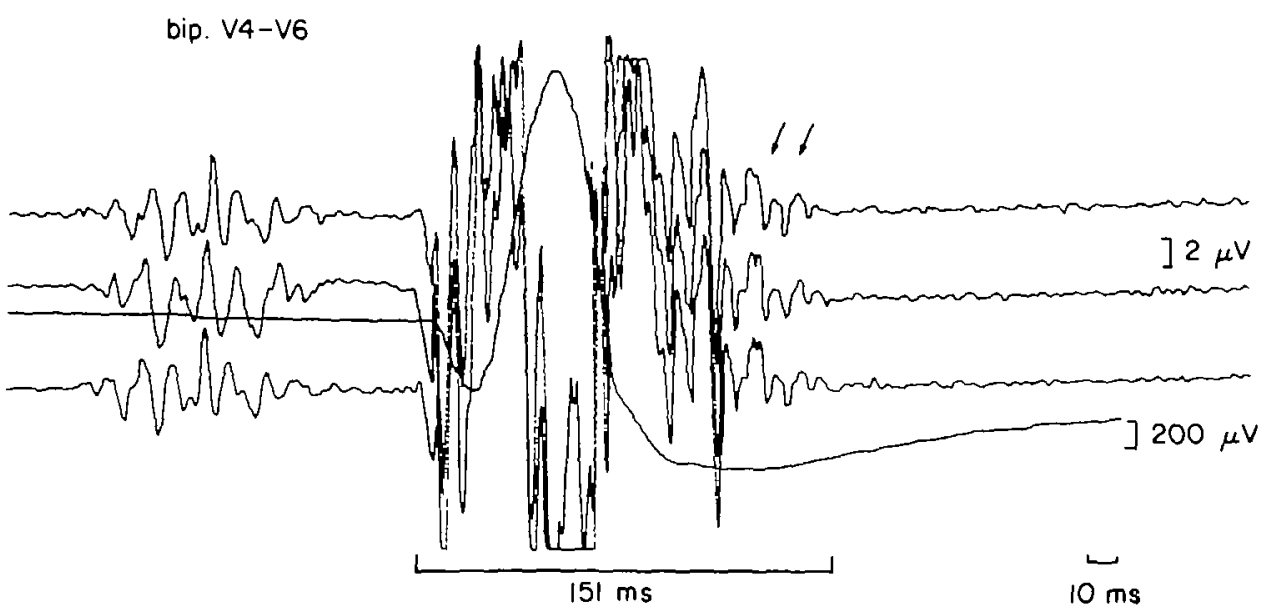

Figure 2 Signal-averaged electrocardiogram obtained in a 38 -year-old patient with idiopathic dilated cardiomyopathy, no bundle branch block but documented episodes of sustained ventricular tachycardia. Bipolar chest lead between V4 and V6; filters $100-300 \mathrm{~Hz}$; paper speed $1000 \mathrm{~mm}$. $\mathrm{s}^{-1}$. Three successive highgain recordings $\left(2 \mu \mathrm{V} . \mathrm{cm}^{-1}\right)$ are displayed (each one obtained by averaging 40 consecutive cardiac cycles) together with a reference electrocardiogram $\left(200 \mu \mathrm{V} . \mathrm{cm}^{-1}\right)$. The total filtered QRS duration is prolonged to $151 \mathrm{~ms}$ and ventricular late potentials (arrows) are identified in the terminal QRS complex.

recording or global left ventricular ejection fraction (Table 5).

\section{FOLLOW-UP DATA $(N=50)$}

During a mean follow-up of $18 \pm 21$ months (range 1-99 months), six patients (12\%) had cardiac transplant, seven patients $(14 \%)$ died, and three patients presented with sustained ventricular tachycardia ( $8 \%)$. The cause of death was due to post-transplant complications in three cases, and was non-cardiac in four cases (two were pulmonary embolisms, one stroke and one toxic hepatitis). The mortality rate was identical in patients with (four out of 22) and in patients without (three out of 28) ventricular late potentials but new episodes of sustained ventricular tachycardia occurred only in patients with ventricular late potentials (three out of 22 patients with vs none out of 28 patients without late potentials, $P<0.05$ ).

\section{Discussion}

The value of signal-averaging for identifying patients with ventricular tachycardia has been established in coronary artery disease, and the prognostic significance of ventricular late potentials after myocardial infarction has been demonstrated in several prospective trials ${ }^{[2-14]}$. However, only few studies have been conducted in patients with non-ischaemic dilated cardiomyopathy, despite the fact that these patients have a high incidence of 


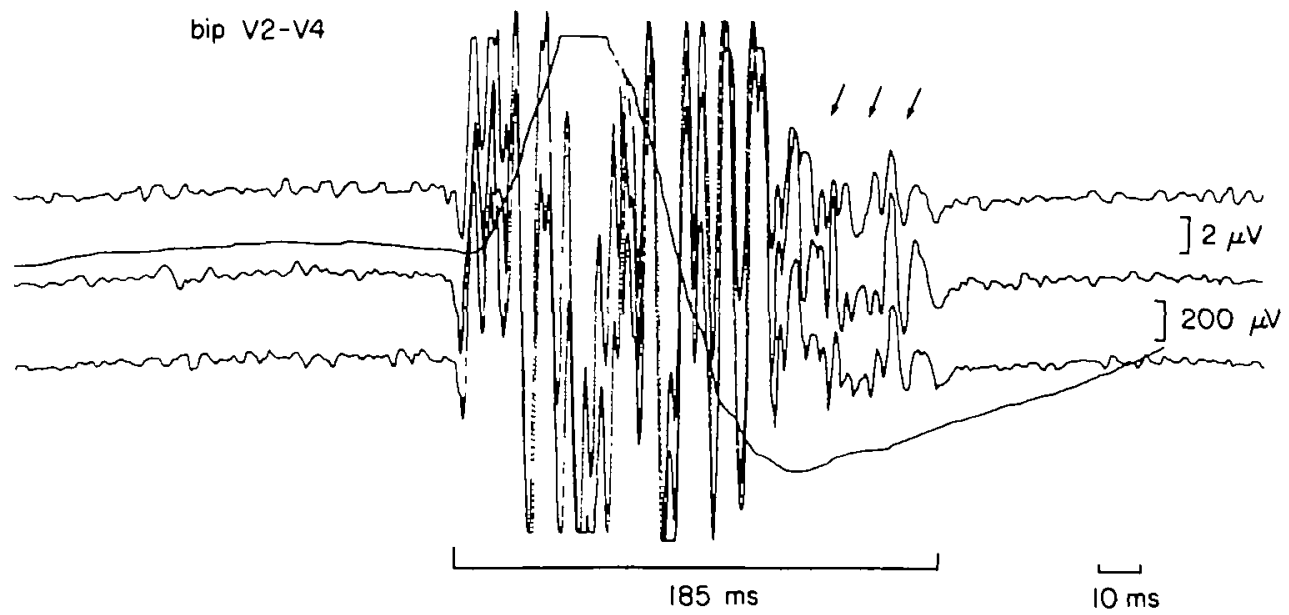

Figure 3 Signal-averaged electrocardiogram obtained in a 49-year-old patient with non-ischaemic dilated cardiomyopathy, complete left bundle branch block and a documented episode of sustained ventricular tachycardia. Bipolar chest lead between V2 and V4; filters $100-300 \mathrm{~Hz}$; paper speed $1000 \mathrm{~mm}$. $\mathrm{s}^{-1}$. Three successive hıgh-gain recordings $\left(2 \mu \mathrm{V} . \mathrm{cm}^{-1}\right)$ are displayed (each one obtained by averaging 40 consecutive cardiac cycles) together with a reference electrocardiogram $\left(200 \mu \mathrm{V} . \mathrm{cm}^{-1}\right)$. The total filtered QRS duration is prolonged to $185 \mathrm{~ms}$ and ventricular late potentials (arrows) are identified in the terminal portion of the QRS complex despite the presence of complete left bundle branch block.

Table I Characteristics of patients with and without ventricular late potentials

\begin{tabular}{lccc}
\hline & VLP+ & VLP- & \\
& $N=22$ & $N=29$ & $P$ \\
& & & \\
\hline & & & \\
Clinical data & & & \\
Mean age (years) & $55 \pm 10$ & $52 \pm 12$ & NS \\
Sex (male/female) & $18 / 4$ & $26 / 3$ & NS \\
Heart failure (III,IV) & $13 / 22$ & $15 / 29$ & NS \\
History of sust. VT & $8 / 22$ & $2 / 29$ & $<0.01$ \\
LBBB & $14 / 22$ & $1 / 29$ & $<0 \cdot 001$ \\
Ns iv conduction dist. & $7 / 22$ & $10 / 29$ & NS \\
Haemodynamic data & & & \\
LV ejection fraction (\%) & $33 \pm 13$ & $32 \pm 11$ & NS \\
EDVI (ml . m ${ }^{-2}$ ) & $155 \pm 50$ & $151 \pm 49$ & NS \\
LVEDP (mmHg) & $17 \pm 7$ & $20 \pm 9$ & NS \\
Holter data & & & \\
VA Lown l1I.IVa +b & $18 / 19$ & $16 / 18$ & NS \\
Non-sustained VT & $13 / 19$ & $11 / 18$ & NS \\
Signal-averaging data & & & \\
Total QRS duration (ms) & $164 \pm 26$ & $113 \pm 10$ & $<0.001$ \\
I-40 (ms) & $70 \pm 20$ & $37 \pm 6$ & $<0.001$ \\
& & & \\
\hline
\end{tabular}

III,IV = functional class according to the New York State Heart Assocation, EDP $=$ end-diastolic pressure, EDVI = end-diastolic volume index, $\mathrm{I}-40=$ interval between the end of the QRS complex and the voltage $40 \mu \mathrm{V}, L V=$ left ventricular, $L B B B=$ left bundle branch block, NS = not significant, ns iv conduction dist. = nonspecific intraventncular conduction disturbance, sust. VT= sustained ventricular tachycardia, VA $=$ ventricular arrhythmias, VLP $=$ ventricular late potentials.

ventricular tachyarrhythmias and sudden death ${ }^{[9.15-18]}$. In the present study, it was found that $43 \%$ of patients with non-ischaemic dilated cardiomyopathy have ventricular
Table 2 Characteristics of patients with and without ventricular late potennals in the absence of left bundle branch block

\begin{tabular}{|c|c|c|c|}
\hline & $\begin{array}{c}\text { VLP }+ \\
N=8\end{array}$ & $\begin{array}{l}\text { VLP- } \\
N=28\end{array}$ & $P$ \\
\hline \multicolumn{4}{|l|}{ Clinical data } \\
\hline Mean age (years) & $5+11$ & $52 \pm 12$ & NS \\
\hline Sex (male/female) & $\overline{7} 1$ & $25 / 3$ & NS \\
\hline Heart failure (III,IV) & $3 / 8$ & $15 / 28$ & NS \\
\hline Sust VT & $4 / 8$ & $2 / 28$ & $<0.01$ \\
\hline Ns iv conduction dist & $7 / 8$ & $10 / 28$ & $<0.01$ \\
\hline \multicolumn{4}{|l|}{ Haemodynamic data } \\
\hline LV ejection fraction (\%) & $37 \pm 14$ & $32 \pm 11$ & NS \\
\hline $\operatorname{EDVI}\left(\mathrm{ml} \cdot \mathrm{m}^{-2}\right)$ & $133 \pm 49$ & $148 \pm 49$ & NS \\
\hline LVEDP $(\mathrm{mmHg})$ & $19 \pm 7$ & $20 \pm 9$ & NS \\
\hline \multicolumn{4}{|l|}{ Holter data } \\
\hline VA Lown III,IVa + b & $7 / 7$ & $15 / 18$ & NS \\
\hline Non-sustained VT & $6 / 7$ & $11 / 18$ & NS \\
\hline \multicolumn{4}{|l|}{ Signal-averaging data } \\
\hline Total QRS duration (ms) & $141 \pm 16$ & $113 \pm 9$ & $<0.001$ \\
\hline I-40 (ms) & $58 \pm 9$ & $37 \pm 6$ & $<0.001$ \\
\hline
\end{tabular}

For key to abbreviations, see Table 1

late potentials and that the presence of late potentials may identify patients with sustained ventricular tachycardia. Thus, in non-ischaemic dilated cardiomyopathy, as in coronary artery disease, signal-averaging appears to be a useful non-invasive test to identify patients with severe ventricular arrhythmias.

Similar results have been reported by others: in a study published by Poll et al. ${ }^{[15]}$, conducted in a group of 41 patients without bundle branch block, $83 \%$ of patients 
Table 3 Characteristics of patients with and without documented sustained ventricular tachycardia

\begin{tabular}{lccc}
\hline & VT + & $V T-$ & \\
& $N=10$ & $N=41$ & $P$ \\
\hline Clinical data & & & \\
$\quad$ Mean age (years) & $50 \pm 11$ & $54 \pm 11$ & NS \\
Sex (male/female) & $9 / 1$ & $35 / 6$ & NS \\
Heart failure (III,IV) & $4 / 10$ & $24 / 41$ & NS \\
LBBB & $4 / 10$ & $11 / 41$ & NS \\
Ns iv conduction dist. & $3 / 10$ & $14 / 41$ & NS \\
Haemodynamic data & & & \\
LV ejection fraction (\%) & $31 \pm 12 \%$ & $32 \pm 12 \%$ & NS \\
EDVI (ml . m ${ }^{-2}$ ) & $154 \pm 52$ & $152 \pm 49$ & NS \\
LVEDP (mmHg) & $19 \pm 8$ & $19 \pm 9$ & NS \\
Holter data & & & \\
VA Lown III,IVa+b & $9 / 9$ & $26 / 28$ & NS \\
Non-sustained VT & $6 / 9$ & $18 / 28$ & NS \\
Signal-averaging data & & & \\
Late potentials present & $8 / 10$ & $14 / 41$ & $<0.01$ \\
Total QRS duration (ms) & $142 \pm 29$ & $129 \pm 30$ & NS \\
I-40 (ms) & $61 \pm 23$ & $54 \pm 21$ & NS \\
\hline
\end{tabular}

For key to abbreviations, see Table I.

Table 4 Characteristics of patients with and without documented sustained ventricular tachycardia in the absence of left bundle branch block

\begin{tabular}{lccc}
\hline & $V T+$ & $V T-$ & \\
& $N=6$ & $N=30$ & $P$ \\
\hline Clinical data & & & \\
$\quad$ Mean age (years) & $46 \pm 10$ & $53 \pm 12$ & NS \\
Sex (male/female) & $5 / 1$ & $27 / 3$ & NS \\
Heart fallure (III,IV) & $0 / 6$ & $18 / 30$ & $<0.01$ \\
Ns iv conduction dist. & $3 / 6$ & $14 / 30$ & NS \\
Haemodynamic data & $38 \pm 11 \%$ & $33 \pm 12 \%$ & NS \\
LV ejection fraction (\%) & $131 \pm 35$ & $147 \pm 52$ & NS \\
EDVI (ml . m-2) & $22 \pm 6$ & $19 \pm 9$ & NS \\
LVEDP (mmHg) & & & \\
Holter data & $6 / 6$ & $16 / 19$ & NS \\
VA Lown III,IVa+b & $4 / 6$ & $13 / 19$ & NS \\
$\quad$ Non-sustained VT & $4 / 6$ & $4 / 30$ & $<0.01$ \\
Signal-averaging data & $133 \pm 18$ & $114 \pm 16$ & $<0.05$ \\
Late potentials present & $54 \pm 15$ & $45 \pm 9$ & $<0.05$ \\
Total QRS duration (ms) & & & \\
I-40 (ms) & & & \\
\hline
\end{tabular}

For key to abbréviatıons, see Table 1.

with sustained ventricular arrhythmias had an abnormal signal-averaged recording vs only $14 \%$ of patients without sustained ventriuclar arrhythmias. In another study ${ }^{(16)}$, parameters of the signal-averaged electrocardiogram seemed to correlate with the clinically documented arrhythmia: patients with a history of monomorphic ventricular tachycardia had a higher incidence of abnormal signal-averaged electrocardiograms than patients with a history of ventricular fibrillation. Results obtained by analysing the signal-averaged recording in the frequency- domain have been comparable: nine out of 10 patients with sustained ventricular tachycardia had late potentials, vs only four out of 21 patients without sustained ventricular tachycardia ${ }^{[19]}$. However, there are controversies concerning the incidence of ventricular late potentials in non-ischaemic dilated cardiomyopathy ${ }^{(9)}$, and a recent study failed to show any correlation between the presence of late potentials and sudden death in patients with advanced heart failure ${ }^{[18]}$. The presence of ventricular late potentials does not seem to be helpful in identifying patients with inducible ventricular tachyarrhythmias in electrophysiological study ${ }^{[16.20]}$. The reason for this descrepancy is unknown, but may be in part related to the low sensitivity and low specificity of programmed ventricular stimulation in non-ischaemic dilated cardiomyopathy ${ }^{[9.21]}$.

Ventricular late potentials are considered a marker for re-entrant ventricular arrhythmias and they are thought to represent delayed activation of some areas of the diseased myocardium ${ }^{[1]}$. The mechanism of ventricular arrhythmias in dilated cardiomyopathy is not established, but recent studies suggest that re-entry is the underlying mechanism for monomorphic ventricular tachycardia in that setting ${ }^{[21.22]}$. Therefore, late potentials may represent the substrate for this type of ventricular arrhythmia in dilated cardiomyopathy. However, in non-ischaemic dilated cardiomyopathy, polymorphic sustained ventricular tachycardia and/or ventricular fibrillation are frequently the only documented ventricular arrhythmias and these arrhythmias are possibly due to other electrophysiological mechanisms, such as abnormal automaticity or triggered activity ${ }^{[16]}$. This may explain some false-negative results of the signal-averaged electrocardiogram in patients with sustained ventricular arrhythmias, and why fractionated ventricular electrograms are less frequently recorded during endocardial mapping in dilated cardiomyopathy ${ }^{[22]}$. In fact, two patients from the present study with documented sustained ventricular tachycardia had a normal signal-averaged electrocardiogram, and in these two cases, ventricular tachycardia was rapid (cycle length $<270 \mathrm{~ms}$ ) and poorly tolerated.

The results of the present study also applied to patients with bundle branch block. Most previous studies on signalaveraging have excluded patients with bundle branch block because intraventricular conduction defects produce severe alterations of the signal-averaged electrocardiogram, and may mimic late potentials ${ }^{[10.11]}$. However, it has been shown that the value of late potentials recording in identifying patients with sustained ventricular arrhythmias is similar in the presence of bundle branch block, if the criteria to define an abnormal recording are adjusted $^{[17.23]}$. Such an adjustment has been made in the present study for left bundle branch block, but the criteria proposed may not be applicable to other signal-averaging devices ${ }^{[17.23]}$.

To identify patients with sustained ventricular tachycardia, late potentials were superior, in this study, to other recognized prognostic factors, such as a low ejection fraction or the presence of non-sustained runs of ventricular tachycardia during Holter monitoring (Table 5). Survival in non-ischaemic dilated cardiomyopathy is strongly 
Table 5 Value of the presence of heart failure, left bundle branch block, ejection fraction less than $40 \%$, non-sustained ventricular tachycardia during Holter monitoring and ventricular late potentials to identify patients with sustained ventricular tachycardia

\begin{tabular}{lccccc}
\hline & $\begin{array}{c}\text { NYHA } \\
\text { III,IV }\end{array}$ & LBBB & EF $<40 \%$ & $\begin{array}{c}\text { Non-sustained } \\
\text { VT }\end{array}$ & $\begin{array}{c}\text { Late } \\
\text { potentials }\end{array}$ \\
\hline Sensitivity (\%) & 40 & 40 & 70 & 67 & 80 \\
Specificity (\%) & 41 & 73 & 23 & 36 & 66 \\
+ Predictive value (\%) & 14 & 27 & 21 & 33 & 36 \\
- Predictive value (\%) & 74 & 83 & 73 & 77 & 93 \\
\hline
\end{tabular}

$\mathrm{VT}=$ ventricular tachycardia.

influenced by the left ventricular function, but the prognostic values of a left bundle branch block, and of Holter monitoring are controversial ${ }^{[2-5.7]}$. In patients of this present study no relation was found between the presence of late potentials and the occurrence of non-sustained ventricular tachycardia during Holter monitoring, possibly because different mechanisms underlie these two phenomena.

\section{LIMITATION OF THE STUDY}

The number of patients is too small and the follow-up period too short in the present study to determine the value of signal-a veraging in predicting prognosis of patients with non-ischaemic dilated cardiomyopathy. Several patients in the study group were on medication at the time of recording and the use of drugs may have influenced both the signal-averaged electrocardiogram and the outcome. Criteria used to define late potentials in the presence of left bundle branch block are difficult to establish and further studies are required, with or without frequency analysis, to make further adjustments of criteria.

\section{CONCLUSION}

In non-ischaemic dilated cardiomyopathy, the signalaveraged electrocardiogram allows the identification of patients with sustained monomorphic ventricular tachycardia even in the presence of left bundle branch block. The exact prognostic significance of this finding, however, remains to be determined.

This study was supported by a grant (No. 3.805-0.86) from the Swiss National Foundation for Scientific Research, Bern, Switzerland.

\section{References}

[1] Johnson RA, Palacios I. Dilated cardiomyopathies of the adult. Part I. N Engl J Med 1982; 307: 1051-8.

[2] Huang SK, Messer JV, Denes P. Significance of ventricular tachycardia in Idiopathic dilated cardiomyopathy: observations in 35 patients. Am J Cardiol 1983; 51: 507-12.

[3] von Olshausen K, Schäfer A, Mehmel HC, Schwarz F, Senges $J$, Kübler $W$. Ventricular arrhythmias in idiopathic dilated cardiomyopathy. Br Heart J 1984; 51: 195-201.

[4] Neri R, Mestroni L, Salvi A, Camerini F. Arrhythmias in dilated cardiomyopathy. Postgrad Med J 1986; 62: 593-7.

[5] Romeo F, Pellicia F, Cianfrocca C, Cristofani R, Reale A. Predictors of sudden death in idiopathic dilated cardiomyopathy. Am J Cardiol 1989; 63: 138-45.
[6] Meinertz T, Hofmann T, Kasper W et al. Significance of ventrcular arrhythmias in idiopathic dilated cardiomyopathy. Am J Cardiol 1984; 53: 902-7.

[7] Unverferth DV, Magorien RD, Moeschberger ML, Baker PB, Fetters JK, Leier CV. Factors influencing the one-year mortality of dilated cardiomyopathy. Am J Cardiol 1984; 54: 147-52.

[8] Holmes J, Kubo SH, Cody RJ, Kligfield P. Arrhythmias in ischemic and nonischmemic dilated cardiomyopathy: prediction of mortality by ambulatory electrocardography. Am J Cardiol 1985; 55: 146-51

[9] Meinertz T, Treese N, Kasper W et al. Determinants of prognosis in idiopathic dilated cardiomyopathy as determined by programmed electrical stimulation. Am J Cardiol 1985; 56: 337-41.

[10] Simson MB. Use of signals in the terminal QRS complex to identify patients with ventricular tachycardia after myocardial infarction. Circulation 1981; 64: 235-41.

[11] Breithardt G, Borggrefe M. Pathophysiological mechanisms and clinical significance of ventricular late potentials. Eur Heart J 1986; 7: 364-85.

[12] Nalos PC, Gang ES, Mandel WJ, Ladenheim ML, Lass Y, Peter T. The signal-averaged electrocardiogram as a screening test for inducibility of sustained ventricular tachycardia in high risk patients: a prospective study. J Am Coll Cardiol 1987; 9: 539-48.

[13] Zimmermann M, Adamec R, Simonin P, Richez J. Prognostic significance of ventricular late potentials in coronary artery disease. Am Heart J 1985; 109: 725-32.

[14] Kanovsky MS, Falcone RA, Dresden CA, Josephson ME, Simson MB. Identification of patients with ventricular tachycardia after myocardial infarction: signal-averaged electrocardiogram, Holter monitoring and cardiac catheterization. Circulation 1984; 70: $264-70$.

[15] Poll DS, Marchlinski FE, Falcone RA, Josephson ME, Simson MB. Abnormal signal-averaged electrocardiograms in patients with nonischemic congestive cardiomyopathy: relationship to sustained ventricular tachyarrhythmias. Circulation $1985 ; 72$ : 1308-13.

[16] Borggrefe M, Egloff J, Budde T, Fetsch T, Karbenn U, Breithardt $G$. Clinical value of late potentials as a marker of electrical instability in dilative cardiomyopathy. In: Santini M, Pistolese M, Alliegro A, eds. Progress in Clinical Pacing. Amsterdam: Excerpta Medica 1988; 247-55.

[17] Brembilla-Perrot B, Terrier de la Chaise A, Suty-Selton C, Marçon F. Effet d'un bloc de branche complet sur le signal moyenné de l'ECG à haute amplification. Arch Mal Coeur $1990 ; 83: 907-12$.

[18] Middlekauff HR, Stevenson WG, Woo MA, Moser DK, Stevenson LW. Comparison of frequency of late potentials in idiopathic dilated cardiomyopathy and ischemic cardiomyopathy with advanced congestrve heart failure and their usefulness in predicting sudden death. Am J Cardiol 1990; 66: 1113-7.

[19] Lindsay BD, Fischer AE, Ambos HD, Markham J, Cain ME. Detection of patients with nonischemic cardiomyopathy prone to sustained ventricular arrhythmias by frequency analysis of 
signal-averaged electrocardiograms. Circulation 1988; 7 : IV-345(Abstr).

[20] Gonksa BD, Bethge Kp, Figulla HR, Kreuzer H. Occurrence and clinical significance of endocardial late potentials and fractionations in idiopathic dilated cardiomyopathy. $\mathrm{Br}$ Heart $\mathrm{J}$ 1988; 59: 39-46.

[21] Poll DS, Marchlinski FE, Buxton AF, Josephson ME. Usefulness of programmed stimulation in 1diopathic dilated cardiomyopathy. Am J Cardiol 1986; 58: 992-7.
[22] Cassidy D, Vassallo JA, Miller JM et al Endocardial catheter mapping in patients in sinus rhythm: relationship to underlying heart disease and ventricular arrhythmias. Circulation 1986: 73: 645-52.

[23] Buckingham TA, Thessen CC, Stevens LL, Redd RM, Kennedy HL. Effect of conduction defects on the signal-averaged electrocardiographic determination of late potentials. Am J Cardiol 1988; 61: 1265-71. 